\title{
Impact of COVID-19 visitor restrictions on healthcare providers in Canadian intensive care units: a national cross-sectional survey
}

\author{
Jennifer M. O'Brien, PhD (D) Faith A. Bae, RN, MN • Joann Kawchuk, MD, FRCPC • \\ Eileen Reimche, BA, BEd, MEd • Candace A. Abramyk • Caitlyn Kitts, BSc • \\ Sana Mohamad · Christine Patterson, MD · Sabira Valiani, MD, FRCPC
}

Received: 7 October 2021/Revised: 14 October 2021 / Accepted: 18 October 2021/Published online: 29 October 2021

(C) Canadian Anesthesiologists' Society 2021

\section{To the Editor,}

A recent environmental scan of Canadian adult intensive care unit (ICU) visitation policies during the first wave of COVID-19 revealed that $86 \%$ of hospitals altered their policies to prohibit or restrict visitors. ${ }^{1}$ The restrictive visitation policies were designed to limit the spread of SARS-CoV-2 and to protect the healthcare workforce in the face of uncertainty, yet often neglected the important role of essential care partners. Meanwhile, fear of infection, elevated workloads, and emotional exhaustion caused stress for healthcare providers. ${ }^{2}$ Critical care providers in the USA identified common concerns including transmitting infection to their families (61\%), emotional distress and burnout (52\%), and concerns about their own health $(44 \%){ }^{3}$ Likewise, a 2003 survey in one Canadian hospital described high levels of stress in healthcare providers despite exposure to relatively few probable or suspect cases of SARS. ${ }^{3}$ Using this survey with established

Supplementary Information The online version contains supplementary material available at https://doi.org/10.1007/s12630021-02139-3.

J. M. O’Brien, PhD ( $₫) \cdot$ J. Kawchuk, MD, FRCPC .

C. Patterson, MD

Department of Anesthesiology, Perioperative Medicine and Pain Management, College of Medicine, University of Saskatchewan, Saskatoon, SK, Canada

e-mail: Jennifer.OBrien@usask.ca

F. A. Bae, RN, MN

College of Nursing, University of Saskatchewan, Saskatoon, SK, Canada

E. Reimche, BA, BEd, MEd - C. A. Abramyk

Patient and Family Partners, Saskatchewan Center for Patient

Oriented Research, Saskatoon, SK, Canada face validity, ${ }^{4}$ we set out to measure the impact of COVID19 visitor restrictions on healthcare providers in Canadian ICUs in the domains of (1) working conditions; (2) factors adversely affecting patient care; (3) communication; and (4) support.

Following ethics approval (5 June 2020), we distributed a survey (Electronic Supplementary Material, eAppendix) through the following professional societies: The Canadian Critical Care Society (564 members) via Twitter and email; The Canadian Association of Critical Care Nurses (1,091 members) via email, the society website, and the society E-newsletter; and The Canadian Society of Respiratory Therapists via posts on Facebook and Twitter, which received about 2,200 views. We estimate that 3,855 healthcare providers received our survey invitation.

Two hundred and twenty-six healthcare providers responded to the survey between June and September 2020 (estimated response rate of $6 \%$ of healthcare providers working in Canadian ICUs during COVID-19). Respondents included intensivists $(23 / 226 ; 10 \%)$, nurses $(162 / 226 ; 72 \%)$, respiratory therapists $(24 / 226 ; 11 \%)$, and

\author{
C. Kitts, BSc \\ College of Medicine, University of Saskatchewan, Saskatoon, \\ SK, Canada \\ S. Mohamad \\ Undergraduate Student Research Assistant (USRA), Saskatoon, \\ SK, Canada \\ S. Valiani, MD, FRCPC \\ Department of Medicine, College of Medicine, University of \\ Saskatchewan, Saskatoon, SK, Canada
}


Figure 1 Compared with my work before COVID-19 visitor restrictions
Compared to my work before the COVID-19 visitor restrictions...

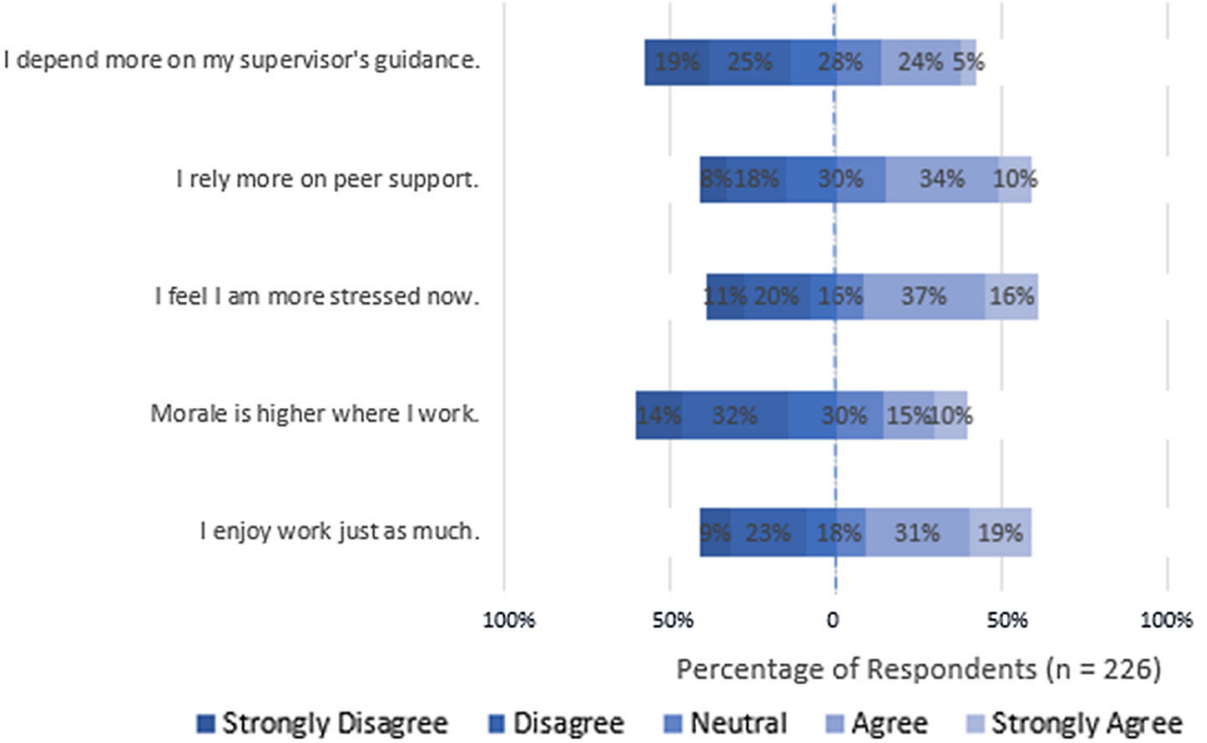

other $(17 / 226 ; 8 \%)$ and came from the following diverse geographic locations: British Columbia (54/226; 24\%), Alberta (28/226; 12\%), Saskatchewan (6/226; 3\%), Manitoba (26/226; 12\%), Ontario (74/226; 33\%), Quebec $(12 / 226 ; 5 \%)$, and Maritime provinces and territories (26/ $226 ; 12 \%)$.

Compared with before the COVID-19 visitor restrictions, some respondents reported increased feelings of stress $(115 / 219 ; 53 \%)$ and decreased morale $(99 / 217$; $46 \%)$, while half of respondents $(108 / 217 ; 50 \%)$ reported enjoying work just as much. Respondents also reported increased reliance on peer support $(95 / 215 ; 44 \%)$ and decreased reliance on supervisors' guidance $(96 / 218 ; 44 \%)$ (Figure 1). The top three sources of morale and personal support regarding COVID-19 visitor restrictions were (1) colleagues in the ICU, (2) family and friends, and (3) supervisors.

When asked about decision-making during COVID-19, most respondents $(109 / 185 ; 59 \%)$ agreed or somewhat agreed with how their hospital handled the outbreak. Most respondents $(115 / 185 ; 62 \%)$ disagreed with the statement "visitor restrictions have not been strict enough." Factors most adversely impacting patient care were reported as infection prevention and control procedures, lack of visitors, and challenges advocating for care. The top three sources of information about COVID-19 visitor restrictions were hospital administration, supervisors, and news media, followed by command centre updates, colleagues in the ICU, and staff in other areas of the hospital.

Our results identify the impact of COVID-19 visitor restrictions on working conditions of healthcare professionals in Canadian ICUs, their sources of morale and personal support, their agreement with decisionmaking and sources of information, and factors perceived to negatively affect patient care. Limitations of our study include the potential for response bias in a small, nonrepresentative sample of healthcare providers in Canadian ICUs. Our findings are limited to Canadian ICUs during the study period, and do not reflect new challenges that have presented themselves since our data were collectedincluding the current fourth wave. Readers may determine if findings are transferable to their settings. A qualitative study exploring what healthcare providers want from their organization during the COVID-19 pandemic identified a desire to be heard, protected, prepared, supported and cared for by the organization. ${ }^{5}$ While most respondents in our study agreed with their hospital's handling of visitor restrictions, the increased levels of stress and decreased morale observed in our study suggest healthcare organizations could benefit by building on the importance of peer support in the ICU and providing clear communication.

Acknowledgements We gratefully acknowledge funding from the University of Saskatchewan College of Medicine Dean's Summer Student program and the University of Saskatchewan Office of the Vice Provost Research Undergraduate Student Research Assistantship, and the Saskatchewan Center for Patient Oriented Research (SCPOR) Trainee Engagement with Patients (STEP) funding.

Disclosures The authors have no conflicts of interest to declare.

Funding statement Caitlyn Kitts was funded through the University of Saskatchewan Dean's Summer Student program. Sana Mohammad was funded through the Undergraduate Student Research 
Assistantship and the Saskatchewan Center for Patient Oriented Research (SCPOR). Eileen Reimche and Candace Abramyk received honoraria through SCPOR.

Editorial responsibility This submission was handled by Dr. Stephan K.W. Schwarz, Editor-in-Chief, Canadian Journal of Anesthesia/Journal canadien d'anesthésie.

\section{References}

1. Fiest KM, Krewulak KD, Hiploylee C, et al. An environmental scan of visitation policies in Canadian intensive care units during the first wave of the COVID-19 pandemic. Can J Anesth 2021; DOI: https://doi.org/10.1007/s12630-021-02049-4.
2. González-Gil MT, González-Blázquez, C, Parro-Moreno AI, et al. Nurses' perceptions and demands regarding COVID-19 care delivery in critical care units and hospital emergency services. Intensive Crit Care Nurs 2021; DOI: https://doi.org/10.1016/J. ICCN.2020.102966.

3. Wahlster S, Sharma M, Lewis AK, et al. The coronavirus disease 2019 pandemic's effect on critical care resources and providers. A global survey. Chest 2020; DOI: https://doi.org/10.1016/j.chest. 2020.09.070.

4. Tolomiczenko GS, Kahan CM, Ricci CM, et al. SARS: coping with the impact at a community hospital. J Adv Nurs 2005; 50: 101-10.

5. Flynn A, Dickey CC. In their own words: what do healthcare workers want from their organization during the COVID-19 pandemic? Healthc Q 2021; 24: 44-9.

Publisher's Note Springer Nature remains neutral with regard to jurisdictional claims in published maps and institutional affiliations. 